\title{
The Patients' View On Accredited Breast Cancer Centers: Strengths and Potential for Improvement
}

\author{
Zertifizierte Brustkrebszentren aus Sicht der Patientinnen: \\ Stärken und Verbesserungspotenziale
}

Authors

Affiliations
C. Kowalski ${ }^{1}$, S. Wesselmann ${ }^{2}$, R. Kreienberg ${ }^{3}$, H. Schulte ${ }^{4}$, H. Pfaff

${ }^{1}$ IMVR - Institut für Medizinsoziologie, Versorgungsforschung und Rehabilitationswissenschaft der Humanwissenschaftlichen Fakultät und der Medizinischen Fakultät der Universität zu Köln, Köln

${ }^{2}$ Deutsche Krebsgesellschaft e. V., Berlin

3 Universitäts-Frauenklinik, Ulm

${ }^{4}$ Frauenselbsthilfe nach Krebs e. V., Bonn
Schlüsselwörter

- Epidemiologie

- Krebsregister

- Mammakarzinom

Key words

- epidemiology

- cancer registry

- breast received 18.11.2011

revised 25.11.2011

accepted $\quad 6.12 .2011$

\section{Bibliography}

Dol http://dx.doi.org/

10.1055/s-0031-1280475

Geburtsh Frauenheilk 2012; 72:

137-143 @ Georg Thieme

Verlag KG Stuttgart · New York

ISSN 0016-5751

\section{Correspondence}

Dr. Christoph Kowalski

IMVR - Institut für Medizin-

soziologie, Versorgungs-

forschung und Rehabilitations-

wissenschaft der Humanwissen-

schaftlichen Fakultät und der

Medizinischen Fakultät

der Universität zu Köln

Eupener Straße 129

50933 Koeln

christoph.kowalski@uk-koeln.de

\section{Abstract}

$\nabla$

Breast Care Centers that were accredited according to the German Cancer Society criteria were offered to participate in a standardized patient survey in 2010, which was conducted by the Institute for Medical Sociology, Health Services Research and Rehabilitation Science, Faculty of Human Science and Faculty of Medicine, University of Cologne. Patients were included consecutively between March and November 2010. The Cologne Patient Questionnaire-Breast Cancer (CPQ-BC) was used, which assesses a number of aspects of hospital care as perceived by the patients, among them provider-patient interaction, the diseasespecific information provided, the quality of organization, and room amenities. 128 of 195 Breast Care Centers and 160 of 251 hospitals participated in the study. 8226 patients consented to the survey. The questionnaires of 7301 patients could be included in the analyses (89\%). Overall, the results showed that patients are satisfied with their hospital stay and that the accreditation criteria are implemented in a way that serves the patients. However, there is room for improvement for a number of issues, for example with regard to the provision of information and patient involvement in decision making. In addition, for a number of indicators substantial differences were found between the hospitals. The results of the survey provide information on the breast centers' development and can be used by the centers' surgery locations for benchmarking purposes, to identify strengths and weaknesses, and to take actions.

\section{Introduction}

In 2010, the breast cancer centres certified in accordance with the criteria of the German Cancer Society (Deutsche Krebsgesellschaft e.V. [DKG]) ${ }^{1}$

\section{Zusammenfassung \\ $\nabla$}

Den nach den Kriterien der Deutschen Krebsgesellschaft e.V. (DKG) zertifizierten Brustkrebszentren wurde im Jahr 2010 angeboten, an einer einheitlichen und für die Häuser kostenlosen Befragung von Patientinnen und Patienten mit primärem Mammakarzinom teilzunehmen. Die Befragung wurde vom Institut für Medizinsoziologie, Versorgungsforschung und Rehabilitationswissenschaft (IMVR) der Humanwissenschaftlichen Fakultät und der Medizinischen Fakultät der Universität zu Köln durchgeführt. Der Einschluss der Patienten erfolgte zwischen März und November 2010. Die Befragung erfolgte postalisch-poststationär. In der Befragung wurde der Kölner Patientinnenfragebogen für Brustkrebs (KPF-BK) eingesetzt. 128 von 195 Brustkrebszentren und 160 von 251 OP-Standorten nahmen an der Patientenbefragung teil. 8226 Patientinnen gaben ihr Einverständnis, an der Befragung teilzunehmen. Insgesamt konnten 7301 Fragebogen in die Auswertung eingeschlossen werden (89\% der angeschriebenen Patientinnen). Die Ergebnisse zeigen eine hohe Zufriedenheit der Patientinnen mit der Versorgung in den DKG-zertifizierten Brustkrebszentren, die Ziele und Inhalte des Zertifizierungssystems werden im Sinne der Patientinnen umgesetzt. Bei einer insgesamt sehr guten Bewertung der Versorgung werden jedoch auch Verbesserungspotenziale für einige der in der Befragung erhobenen Aspekte ersichtlich. Zutage treten zudem teilweise deutliche Unterschiede zwischen den Brustkrebszentren. 
of Humanities and the Faculty of Medicine of the University of Cologne. The aim of the survey was to record comparable data from as many breast cancer centres as possible by means of cross-hospital, uniform questionnaires and survey design in order to allow for a comparison between the results of the different hospitals, e.g. for the purpose of benchmarking. The processing of the survey and the survey instrument are largely identical to the patient surveys conducted according to the criteria of the certified breast centres in North Rhine-Westphalia since 2006. The "Cologne patient questionnaire for breast cancer" (KPF-BK), which surveys a variety of subareas of health care provision in hospitals as well as health-related quality of life, was used. Clinical and treatment data were supplemented by the hospital staff [1]. The survey presented here was free of charge for the participating hospitals. An advantage for the hospitals was that the participation in the survey fulfilled a requirement for (re-)certification. Nearly two thirds of the DKG-certified breast cancer centres participated in the survey. The implementation of the survey, the questionnaire and selected results are presented here.

\section{Materials and Methods}

$\nabla$

All DKG-certified breast cancer centres were offered participation in the survey. As the breast cancer centres in North RhineWestphalia, which are certified according to the criteria of the federal state, were participating in a mandatory survey at the same point in time, these centres were not offered participation in the survey described here. Information about the survey and all documents required for the survey were sent to all breast cancer centres included in the survey and all their operational sites. Patients undergoing surgery during the survey period were asked for their consent to participate in the study shortly before their discharge. The inclusion criteria included in particular: surgery during the current hospital stay, initial diagnosis, i.e. no local recurrence, discharge during the survey period: 22nd March until 30th November 2010, at least one malignant finding, at least one post-operative mammary carcinoma histology, and ICD code of the verified diagnosis: C50.x or D05.x.

Subject to the consent of the patients, the hospitals submitted the clinical indicators (including grading, tumour size, nodular status, metastases and type of operation) and the addresses once per week to the IMVR, which then sent out the questionnaires to the patients.

The expenditure for the participating breast cancer centres was therefore manageable. The declarations of consent were collected and sent to the IMVR once per week. The survey was then conducted by post and, following the hospital stay, in accordance with the "Total Design Method" [2]. The first letter sent included a postage paid return envelope and two reminder letters. ${ }^{2}$

The Cologne patient questionnaire for breast cancer (KPF-BK) was used for the survey. This is a modular questionnaire which measures a multitude of partial performance dimensions of treatment on the ward, with more than 60 key indicators. These include e.g. the admission procedure, the interaction with staff as perceived by the patients, the quality of the accommodation, the quality of the information provided about the treatment and psycho-social support, and overall satisfaction. In addition, the health-related quality of life and socio-demographic information of the patients were collected with the EORTC modules.

In most cases the items of the various key indicators in the KPF-BK were subjected to factor analysis and reliability tests and then added on a scale (indicator) and divided by the number of items. The items were encoded in such a way that disapproval of a statement was assigned low values and approval high values (e.g. "do not agree at all" = one point or "completely agree" $=4$ points). The range of values of the indicators is usually between one and four. The indicator names were chosen in such a way that a high value corresponds to agreement with the substantive meaning of the name and a low value to disapproval of this meaning. Accordingly, a high value such as "support by doctors" expresses the opinion that the patients felt they had been well supported by the medical staff during their stay in hospital. The 22 indicators treated in this way are presented in the first part of the results report. The presentation of the individual items then follows. The complete report is available on the websites of the DKG and the IMVR. ${ }^{3}$ Selected results are presented in the present paper.

\section{Results \\ $\nabla$}

128 of 195 DKG-certified breast cancer centres and 160 of the 251 surgical locations participated in the patient survey. 8226 of the 9354 patients who were asked for their consent were prepared to take part in the survey ( $\bullet$ Fig. 1). A questionnaire was sent to all 8226 patients agreeing to take part in the survey. A total of 7405 replies were received from the patients. For different reasons 87 patients were not able to participate in the survey. ${ }^{4}$ 7318 patients sent back the completed questionnaire. 17 questionnaires could not be included in the analysis, as only $30 \%$ or less of all questions had been answered. The analysis thus included a total of 7301 questionnaires: $88.76 \%$ of the surveys sent to patients were therefore suitable for evaluation. The number of completed and evaluable questionnaires from the individual breast cancer centres ranged from 1 to 166. In order to ensure the anonymity of the respondents, only results from centres from which at least 6 evaluable questionnaires were received were included in the report.

The high return quota and the very satisfactory participation rate of the hospitals testify that the random sampling for the included collective was highly representative. The results in respect of the age of the respondents and type of operation confirm this ( $\bullet$ Tables 1 and 2 ).

The survey data were prepared for the participating breast cancer centres in the form of a results report. This report compared the results of all indicators for the different breast centres. The presentation is in pseudonymised form: the breast cancer centres are identified by a number which is available only to the respective breast cancer centre. In this way, the centres are able to compare their own evaluation with those of the other centres with-

\footnotetext{
${ }^{1}$ Male and female patients were included in this survey. As mainly women were surveyed, the term "patients" here includes mainly women. 32 questionnaires completed by men were also assessed.

2 For a more detailed description of the survey implementation, please see [3].

3 http://www.imvr.uni-koeln.de/uploads/Ergebnisbericht\%20DKG\%20Patientenbefragung\%202010.pdf;

http://www.krebsgesellschaft.de/wub_zertifizierte_zentren_aktuelles,200746.html

${ }^{4}$ The reasons for this were for example: incorrect inclusion in the survey, poor state of health, language barriers, and deceased patients.
} 


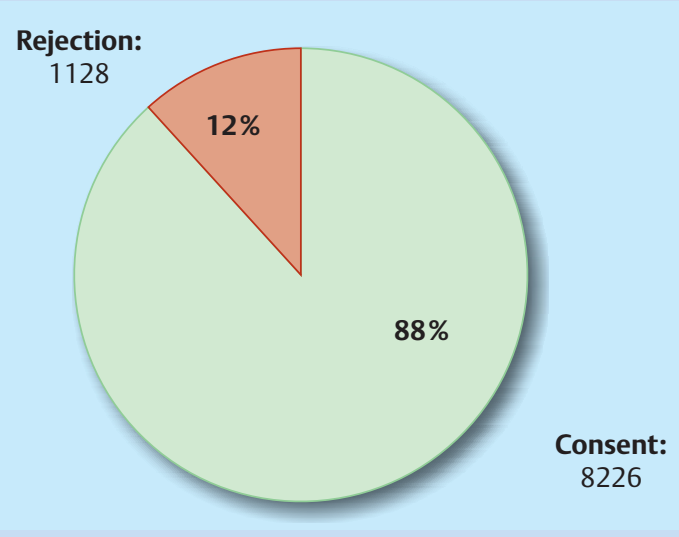

Fig. 1 Declarations of consent: consent and rejection of survey.

out their identity being apparent to others. The report can be downloaded by the general public, however not the identification numbers. The results serve as a comparison of breast cancer centres with each other, the analysis of strengths and weaknesses, and as a starting point for measures for improvement in the sense of the implementation of the ideal of a "learning hospital" [3].

Overall, the results demonstrated a high level of patient satisfaction with the treatment in the DKG-certified breast cancer centres. For example, only a few patients were dissatisfied with their medical treatment and the cleanliness of the hospitals. The trust in doctors and nursing staff is also exceptionally high. However, clear potential for improvement was demonstrated, for example in terms of the provision of information and inclusion of patients in their treatment. In addition, in part distinct differences exist between the different breast cancer centres.

Exemplary selected results of the survey on the subjects of opting for a breast cancer centre, support by doctors and nursing staff, provision of information and self-help are presented. Furthermore, regional differences are examined.

Table 1 Age distribution of patients in \% (n).

\begin{tabular}{|lrr|}
\hline Age in groups & \multicolumn{1}{c}{$\%$} & \multicolumn{1}{c|}{$\mathbf{n}$} \\
\hline 18 to 29 years & 0.5 & 38 \\
\hline 30 to 39 years & 3.5 & 250 \\
\hline 40 to 49 years & 17.4 & 1256 \\
\hline 50 to 59 years & 27.3 & 1976 \\
\hline 60 to 69 years & 29.6 & 2143 \\
\hline 70 to 79 years & 17.3 & 1252 \\
\hline 80 years and older & 4.4 & 319 \\
\hline Total & 100 & 7234 \\
\hline No information & & 67 \\
\hline
\end{tabular}

Table 2 Type of operation (information by hospital staff) in \% (n).

\begin{tabular}{|lrr|}
\hline Type of surgery & \multicolumn{1}{c}{ \% } & \multicolumn{1}{c|}{ n } \\
\hline Mastectomy without direct reconstruction & 20.1 & 1379 \\
\hline Mastectomy with direct reconstruction & 4.8 & 326 \\
\hline Breast-conserving therapy & 74.5 & 5115 \\
\hline Other information & 0.6 & 43 \\
\hline Total & 100 & 6863 \\
\hline No information & & 438 \\
\hline
\end{tabular}

\section{Deciding on a breast cancer centre}

When asked about the reasons for the decision on the treating breast cancer centre, patients mostly stated recommendation, reputation of the breast cancer centre, proximity to place of residence and certification. The reputation of a doctor was mentioned by approximately one third of all patients ( Table 3).

For the most mentioned reason of "recommendation", the KPF-BK includes a question about the person recommending the centre. The gynaecologist was mentioned most often as the source of recommendation (59.4\%); however, $12 \%$ of patients also named relatives/acquaintances as the source of recommendation.

\section{Support by doctors and nursing staff}

The level of "support by doctors" was ascertained on the basis of three items ( Table 4). The individual questions can be interpreted on their own or as an index, according to the scale structure. Overall, it was demonstrated that a high level of doctor's support was perceived by the patients. An overall mean value of 3.53 on a scale from one to four was found. Clear differences exist between the breast cancer centres. Accordingly, the mean values per centre range from 3.07 to 3.85 .

The indicator "support by nursing staff" shows comparable results. An overall mean value of 3.58 was found, while the mean values of the centres range between 3.13 and 3.87. The results of the items are summarised in $\bullet$ Table 5.

\section{Information}

While staff-related indicators (support and trust in doctors and nursing staff) as well as the indicators of room quality (e.g. cleanliness and room equipment) showed good overall results, the potential for improvement became clear in terms of the extent of information and the way information is provided. This is demonstrated here for the example of the indicator "emphatic communication of information" and the need of information following discharge, the "psycho-social need for information".

Fewer patients indicated their satisfaction with the five items of emphatic communication of information by the doctor ( Table 6) than on questions about the support by the medical staff. The scale mean value for all patients is 3.40 ; the best value for a breast centre is 3.69 and the worst 3.04. The results on the indicator "psycho-social need for information" indicate the subjects for which the patients would have liked more information ( Table $7)$.

Table 3 Decision factors for the selection of the breast centre (ticks in \% and n).

\begin{tabular}{|c|c|c|}
\hline \multirow{2}{*}{$\begin{array}{l}\text { Which factors mainly influenced you } \\
\text { in your decision on the breast centre? } \\
\text { (multiple answers possible) }\end{array}$} & \multicolumn{2}{|c|}{ ticked } \\
\hline & $\%$ & $\mathbf{n}$ \\
\hline Proximity to place of residence & 43.2 & 3156 \\
\hline Recommendation & 45.7 & 3335 \\
\hline Certification (= quality seal) of breast centre & 35.8 & 2616 \\
\hline Good reputation of the breast centre & 43.6 & 3186 \\
\hline Specialised treatment options & 11.0 & 806 \\
\hline Good reputation of a doctor in the breast centre & 31.2 & 2281 \\
\hline Own good experience with the hospital & 17.4 & 1267 \\
\hline Information which I found in the Internet. & 4.8 & 351 \\
\hline Other & 3.6 & 265 \\
\hline No answer ticked & & 61 \\
\hline
\end{tabular}


Table 4 Support by doctors, scale items in \% (n).

\begin{tabular}{|c|c|c|c|}
\hline \multirow[t]{2}{*}{ What is your opinion of the doctors on the ward? } & Disapproval $(1,2)$ & Approval $(3,4)$ & No information \\
\hline & $\%(n)$ & $\%(n)$ & $\mathbf{n}$ \\
\hline I could rely on the doctor when I had problems with my illness. & $4.9(346)$ & $95.1(6753)$ & 202 \\
\hline The doctors supported me in such a way that dealing with my illness was easier. & $10.8(769)$ & $89.2(6354)$ & 178 \\
\hline The doctors were prepared to listen to the problems relating to my illness. & $9.7(691)$ & $90.3(6415)$ & 195 \\
\hline
\end{tabular}

Table 5 Support by nursing staff, scale items in \% (n).

\begin{tabular}{llll} 
What is your opinion of the nursing staff on the ward? & $\begin{array}{l}\text { Disapproval }(\mathbf{1}, \mathbf{2}) \\
\text { \% (n) }\end{array}$ & $\begin{array}{l}\text { Approval }(\mathbf{3}, \mathbf{4}) \\
\text { \% (n) }\end{array}$ & $\begin{array}{l}\text { No information } \\
\mathbf{n}\end{array}$ \\
\hline I could rely on the nursing staff when I had problems with my illness. & $3.6(257)$ & $\mathbf{9 6 . 4}(6865)$ & 179 \\
\hline The nursing staff supported me in such a way that dealing with my illness was easier. & $6.3(447)$ & $\mathbf{9 3 . 7}(6680)$ & 174 \\
\hline The nursing staff was prepared to listen to the problems relating to my illness. & $10.1(715)$ & $89.9(6358)$ & 228
\end{tabular}

When patients expressed a desire for additional information, this was mostly concerned with the physical and nervous stress in daily life resulting from the treatments (36\%) and the health-promoting measures (39\%). How this need for information could be met often remained open at this point. The comparatively low number of patients who would have liked more information on books and brochures suggests that patients prefer to receive information from "personal sources", e.g. the hospital staff. This refers not only to doctors, but also to qualified (specialised) nursing staff.

\section{Self-help}

As can be seen from - Table 7, $80 \%$ of the patients stated that they do not require more information on self-help groups. For many patients, however, self-help groups are of great importance if support is required during and after a hospital stay. The KPF-BK was developed in collaboration with self-help groups and other parties and thus also documents the contact to and information about self-help groups in the two questions shown in 0 Table 8. The majority of patients stated that they had been informed about self-help groups in the hospital; a further $15 \%$ indicated that they had no interest in this information. However, $28.5 \%$ of the patients had not been informed. This percentage varies considerably between the breast cancer centres. In the best breast cancer centre, no patient indicated that she/he had not been provided with information about self-help groups; in the six worst centres, this percentage was, however, above 60\% (results not shown). Just under $7 \%$ of the patients also had contact to selfhelp groups during their stay in hospital, and one fifth expressed no interest in this. 73\% had no contact. Again, this percentage of patients differs significantly between the different breast cancer centres (minimum: 34\%, maximum: 93\%).

\section{Regional differences}

The survey presented enables a comparison between the assessments of mamma carcinoma patients for the entire Federal Republic of Germany and therefore allows conclusions about regional differences for selected indicators. The federal states are summarised in groups for the results presented in 0 Table 9, for which evaluable results were available in overall at least four centres.

Table 6 Empathetic communication of information, scale items in \% (n).

\begin{tabular}{|c|c|c|c|}
\hline \multirow[t]{2}{*}{ The doctors on the station ... } & Disapproval $(1,2)$ & Approval $(3,4)$ & No information \\
\hline & $\%(n)$ & $\%(n)$ & $\mathbf{n}$ \\
\hline ... informed me about the breast cancer diagnosis empathetically. & $15.4(1070)$ & $84.6(5903)$ & 328 \\
\hline ... explained the further treatment steps with sensitivity. & $14.4(1020)$ & $85.6(6074)$ & 207 \\
\hline ... explained procedures in detail. & $12.2(868)$ & $87.8(6262)$ & 171 \\
\hline ... explained procedures in an understandable way. & $10.6(758)$ & $89.4(6365)$ & 178 \\
\hline ... gave me sufficient time for consideration. & $16.1(1121)$ & $83.9(5825)$ & 355 \\
\hline
\end{tabular}

Table 7 Psycho-social information requirements, scale items in \% (n).

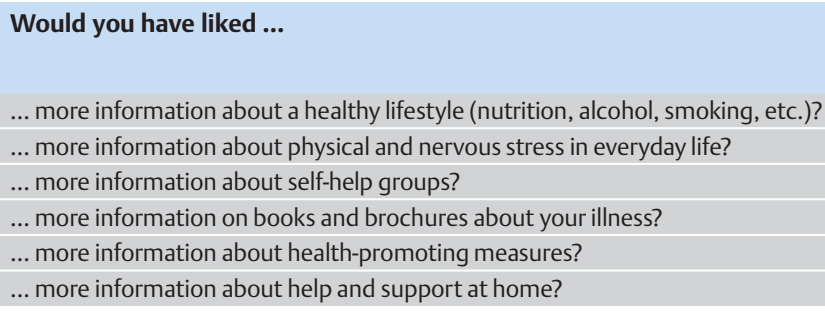

\begin{tabular}{llll} 
No (1) & Yes (2) & Don't know & No information \\
$\mathbf{\%}(\mathbf{n})$ & $\mathbf{\%}(\mathbf{n})$ & $\mathbf{\%}(\mathbf{n})$ & $\mathbf{n}$ \\
$\mathbf{7 0 . 0}(5019)$ & $24.2(1733)$ & $5.8(414)$ & 135 \\
\hline $\mathbf{5 7 . 6}(4117)$ & $36.0(2569)$ & $6.4(459)$ & 156 \\
\hline $\mathbf{8 0 . 0}(5711)$ & $13.6(969)$ & $6.4(457)$ & 164 \\
\hline $\mathbf{8 3 . 2}(5945)$ & $12.1(867)$ & $4.6(330)$ & 159 \\
\hline $\mathbf{5 5 . 8 ( 3 9 7 2 )}$ & $39.0(2778)$ & $5.2(372)$ & 179 \\
\hline $\mathbf{7 2 . 7}(5170)$ & $19.3(1369)$ & $8.0(568)$ & 194 \\
\hline
\end{tabular}


Table 8 Information and contact with self-help groups in \% (n).

\begin{tabular}{lllll} 
What is your opinion? & No & Yes & Did not want & No information \\
& $\%(\mathbf{n})$ & $\%(\mathbf{n})$ & $\%(\mathbf{n})$ & $\mathbf{n}$ \\
Were you informed about self-help groups in the hospital? & $28.5(2047)$ & $56.3(4042)$ & $15.2(1092)$ & 120 \\
\hline Did you have any contact with self-help groups during your hospital stay? & $\mathbf{7 3 . 0}(5184)$ & $6.9(488)$ & $20.2(1433)$ & 196
\end{tabular}

Table 9 Regional differences in the scale results: Mean values of centre mean values by region (number of breast cancer centres included).

\begin{tabular}{|llllll|}
\hline & $\begin{array}{l}\text { Admission } \\
\text { process }\end{array}$ & $\begin{array}{l}\text { Client-friendly } \\
\text { infrastructure }\end{array}$ & $\begin{array}{l}\text { Support by } \\
\text { doctors }\end{array}$ & $\begin{array}{l}\text { Support by } \\
\text { nursing staff }\end{array}$ & $\begin{array}{l}\text { Empathetic communi- } \\
\text { cation of information } \\
\text { Baden-Wuerttemberg (23) }\end{array}$ \\
\hline Bavaria (26) & 3.66 & 3.55 & 3.47 & 3.52 & 3.38 \\
\hline Berlin (6) & 3.61 & 3.46 & 3.50 & 3.56 & 3.37 \\
\hline Brandenburg/Mecklenburg-Western Pomerania (4) & 3.60 & 3.35 & 3.44 & 3.53 & 3.40 \\
\hline Hesse(13) & 3.42 & 3.63 & 3.67 & 3.63 & 3.42 \\
\hline Lower Saxony/Bremen (16) & 3.46 & 3.46 & 3.44 & 3.42 & 3.31 \\
\hline Rhineland-Palatinate/Saarland/NRW (9) & 3.60 & 3.53 & 3.53 & 3.58 & 3.37 \\
\hline Saxony (8) & 3.59 & 3.54 & 3.55 & 3.57 & 3.36 \\
\hline Saxony-Anhalt(6) & 3.71 & 3.61 & 3.64 & 3.67 & 3.44 \\
\hline Schleswig-Holstein/Hamburg (4) & 3.65 & 3.59 & 3.64 & 3.66 & 3.53 \\
\hline Thuringia (6) & 3.71 & 3.31 & 3.57 & 3.62 & 3.45 \\
\hline Total & 3.63 & 3.49 & 3.65 & 3.63 & 3.49 \\
\hline
\end{tabular}

The table summarises the mean values for the centres in respect of the indicators "admission procedure", "client friendly infrastructure", "support by doctors", "care support" and "emphatic communication of information" for the 121 German breast cancer centres for which evaluable figures were available. It should be noted that these differences can be the result of regional characteristics of the respondents, e.g. patients from certain regions could have higher expectations in terms of treatment, while patients in other regions of Germany are more easily satisfied. However, the results do not support this, as otherwise similar tendencies would have been expected for all indicators in all regions. For example, Brandenburg/Mecklenburg-Western Pomerania showed the best results for a client-friendly infrastructure and support by doctors, however at the same time the worst results for the admission procedure. Overall only minor regional differences, with a slight tendency to overall better result, were found for the East German federal states.

\section{Discussion}

\section{$\nabla$}

With over 7000 participating patients and 160 participating hospitals this study represents one of the largest surveys of breast cancer patients in Europe. For the evaluation of the results it is firstly important to examine the prerequisites of a certified centre. According to the definition of the National Cancer Plan, certified centres are "a network of qualified and jointly certified, interdisciplinary and trans-sectoral [...] facilities, which $[\ldots]$ form the entire care chain for those affected [...]" [4]. This means that, with this certification, a network is formed for the patients in which all medical disciplines and, in particular, all professional groups work together trans-sectorally in order to provide competent and trustworthy contacts for patients in any area of their illness.

Are these conditions reflected in the patients' experiences and thus in the results of the survey?
The survey was conducted by post following the hospital stay; the vast majority of the patients were therefore in the early stage of an overall treatment. Only $7.6 \%$ of the patients had received neo-adjuvant chemotherapy prior to surgery. In summary, $94.3 \%$ of patients were satisfied with their hospital stay and would recommend their centre.

When examining the results of the scales and items individually, the trust towards doctors and nursing staff is particularly noticeable. Patients had full confidence in staff (97.3\% doctors, $96.7 \%$ nursing staff) and rated them as very competent ( $98.4 \%$ doctors, $97.2 \%$ nursing staff). Furthermore, they stated that they felt they had been well supported by the medical staff and that this resulted in their being able to deal more effectively with the illness (89.2\% doctors, $93.7 \%$ nursing staff). The patients were also very satisfied with the explanations given by doctors on their diseases and on the benefits and risks for the selected treatment. However, $12.6 \%$ indicated that they received only little or no information on various alternative treatment options. This is probably due to the fact that, based on clinical findings, for the majority of the surveyed patients a standardised approach for treatment steps was followed; e.g. $74.5 \%$ of patients received breast-conserving therapy. In addition, more than one third of the patients would have liked more information on general health-promoting measures and on the physical and nervous stress in everyday life as a result of the illness and therapy.

It also remarkable that for $35.8 \%$ of the respondents the certification of the breast cancer centre played a key role when deciding on a clinic. $59.4 \%$ of the patients followed the recommendation of their gynaecologist when deciding on a clinic. The importance of referring doctors and, to a lesser extent, certification was also underscored as a selection criterion for patients by Lux and colleagues [5]. This is most probably due to the comparatively high level of awareness of the concept of certified breast cancer centres [6].

The information about and the contact to other professional groups and organisations integrated in the certified centres is rated differently by the patients. For example, $31 \%$ of the patients 
would have liked more information about rehabilitation options, which is primarily provided by the social workers in the centres. Around $18 \%$ of patients stated that they had not received sufficient information about possible psycho-oncological support, and approximately $11 \%$ of the patients were sooner dissatisfied with the psycho-oncological support they had received. Also, the information on the self-help groups was not provided to all patients; $28 \%$ of patients were not informed about self-help groups, however here the point in time of the survey may have been a factor.

A further important area within the certified centres is the organisation of the interdisciplinary cooperation and the processes within the network. While the organisation of admission to the centres was perceived as good by the patients, waiting periods often occurred in connection with admission and also for examinations and procedures (24.3\%). Discharge from hospital was rated very positively, in particular the explanation of the further treatment steps (93.8\% of patients) and the preparation for additional interdisciplinary treatment (90.8\%).

The DKG-certified breast cancer centres in North Rhine-Westphalia were not included in the survey, in so far as these had been certified in accordance with the requirements of the federal state of North Rhine-Westphalia, which means that they had already participated in a survey with an almost identical questionnaire. This survey overlapped with the study presented here. A comparison of the results of both surveys is possible only to a limited extent for a number of indicators, as potential differences may be associated with the different survey periods or different lengths of the questionnaires. This comparison and the analysis of the weighting of individual aspects by patients could be the subject of further studies. There is also a potential for correlation analyses, for example the correlation between satisfaction and primary case numbers or the results of the key person survey [7]. In summary, it can be said that the survey of the patients in the breast case centres demonstrates that the prerequisites and content of the certified centres according to the definition of the National Cancer Plan are well reflected in the day-to-day operations of the centres. Patient support is of a very high standard, and this is reflected in the overall very good results. However, as demonstrated, there are areas in which potential for improvement exists, both in the individual centres and in respect of all centres. The differences in the results between the individual centres are in part considerable. Particularly in these cases the individual analyses, which were made available to the centres, are an important tool for the identification of strengths and weaknesses in their own networks and for discussion in the centre's governing bodies. In this way, processes and structures can be critically examined with the patient as focus based on a classic PDCA cycle and, if required, modified. In addition, after the conclusion of the survey, a workshop was held for the representatives of the centres in which the content and the results of the survey were more closely discussed. This was conducted by the German Cancer Association in cooperation with the "Women's self-help following cancer group" and the Institute for Medical Sociology, Health Services Research and Rehabilitation Science (IMVR). In this context, the centres which had achieved particularly good results for selected subject areas presented their experiences and structures. These were then discussed together in order to learn from the procedures of others in the sense of benchmarking.

\section{Conclusion for Practice}

$\nabla$

The analysis of the survey shows that the objectives and contents of certified centres as specified in the definition of the National Cancer Plan are well implemented in the centres. The interdisciplinary, cross-professional and trans-sectoral cooperation of the partners involved is reflected in the patients' experiences and therefore in the results of the survey. Patients are very well cared for in the certified breast cancer centres; this was made clear by a number of individual aspects. The support of or confidence in doctors and the nursing staff who make dealing with the illness easier for the patients, listen to them and on whom the patients rely, was rated as particularly positive. Potential for improvement could be shown for a number of aspects in the survey, such as in the area of providing information as discussed in this study. Furthermore, in part significant differences were revealed between the breast cancer centres. Regional differences were negligible. The presentation of results in the result report of individual centres allows the analysis of the strengths and weaknesses of an individual breast cancer centre in comparison with the other breast cancer centres. This can be utilised by the breast cancer centres for the initiation of targeted measures in the sense of a "learning hospital". The experience gained in previous years in North Rhine-Westphalia shows that the results of the survey can be used successfully and that improvements can be observed over time [8]. The goal of each breast cancer centre should be the improvement of the results. From the perspective of the patients it is also important that the differences between the hospitals are reduced and that both the quality of medical treatment and patient orientation is of the highest standard nationwide [9].

\section{Acknowledgement \\ $\nabla$}

We would like to thank the patients who participated in this study, the breast centres supporting this survey, and AVON for generously funding the study.

\section{Conflict of Interest}

None.

\section{References}

1 Kowalski C, Nitzsche A, Scheibler F et al. Breast cancer patients' trust in physicians: The impact of patients' perception of physicians' communication behaviors and hospital organizational climate. Pat Educ Couns 2009; 77: 344-348

2 Dillman DA. Mail and Telephone Survey: the total Design Method. New York: Wiley \& Sons; 1978

3 Pfaff H. Das lernende Krankenhaus (The learning hospital). Z f Gesundheitswiss 1997; 5: 323-342

4 http://www.bmg.bund.de/fileadmin/dateien/Downloads/N/ Nationaler_Krebsplan/Zielpapier5_Nationaler_Krebsplan_ onkologische_Versorgungsstrukturen_110623.pdf; last access: 14.07.2011

5 Lux MP, Fasching PA, Schrauder M et al. The era of centers: the influence of establishing specialized centers on patients' choice of hospital. Arch Gynecol Obstet 2011; 283: 559-568

6 Lux MP, Fasching PA, Bani MR et al. Marketing von Brust- und Perinatalzentren - Sind Patientinnen mit dem Produkt „zertifiziertes Zentrum“ vertraut? (Marketing of breast and perinatal centres - Are patients familiar with the concept of „certified centre“? Geburtsh Frauenheilk (Obstetrics and gynaecology) 2009; 69: 321-327 
7 Kowalski C, Wesselmann S, Ansmann L et al. Key informants' perspectives on accredited breast cancer centres: results of a survey. Geburtsh Frauenheilk 2012; 72: 135-141

8 Kowalski C, Würstlein R, Steffen $P$ et al. Vier Jahre Patientinnenbefragung im Rahmen der (Re-)Zertifizierung der Brustzentren in Nordrhein-Westfalen. (Four years of patient surveying in the context of [re-]certification of breast cancer centres in North Rhine-Westphalia). Geburtsh Frauenheilk (Obstetrics and gynaecology) 2011; 71: 67-72
9 Selby JV, Schmittdiel JA, Lee J et al. Meaningful variation in performance: What does variation in quality tell us about improving quality? Medical Care 2010; 48: 133-139

Deutschsprachige Zusatzinformationen mit deutschem Text online abrufbar unter: www.thieme-connect.de/ejournals/toc/gebfra. 